\title{
Organizing pneumonia in textile printing workers: a clinical description
}

\author{
S. Romero*, L. Hernández*, J. Gil*, I. Aranda**, C. Martín*, J. Sanchez-Payát
}

\begin{abstract}
Organizing pneumonia in textile printing workers: a clinical description. S. Romero, $L$. Hernández, J. Gil, I. Aranda, C. Martín, J. Sanchez-Payá. CERS Journals Ltd 1998.

ABSTRACT: In April 1992 an outbreak of severe respiratory illness occurred among aerographic textile workers in the area of Alcoi, Autonomous Community of Valencia, Spain. An epidemiological study linked this outbreak to the use of a reformulated aerosolized product, Acramin-FWN.

We analyzed clinical, laboratory, and pathological data of the first 14 patients with confirmed organizing pneumonia (OP) secondary to this newly recognized occupational toxicant.

The mean age of the patients was $30 \mathrm{yrs}$. The most common clinical findings were cough $(86 \%)$, epistaxis $(71 \%)$, dyspnoea $(64 \%)$, oppressive chest pain $(57 \%)$, and crackles $(50 \%)$. A restrictive functional pattern was evident in $64 \%$. Radiographic findings consisted predominantly of patchy infiltrates in $65 \%$ and a micronodular pattern in $35 \%$. Treatment with corticosteroids did not prevent initial progression in 11 of the 14 patients and development of irreversible respiratory failure in five patients. At necropsy, besides features of OP, interstitial fibrosis and diffuse alveolar damage were evident. A low total lung capacity, the presence of crackles at admission, and increases in the alveolar-arterial oxygen difference were predictive of death.

The organizing pneumonia caused by the inhalation of Acramin-FWN is characterized by a tendency to evolve into progressive interstitial fibrosis despite the use of corticosteroids. The illness is restricted to the respiratory system and once respiratory failure has developed the prognosis is poor.

Eur Respir J 1998; 11: 265-271.
\end{abstract}

*Servicios de Neumología, **Anatomía Patológica and +Medicina Preventiva, Hospital General Universitario de Alicante, Alicante, Spain.

Correspondence: S. Romero,

C/Italia 30

2a escalera

$1^{\circ}$ Derecha

03003 Alicante

Spain

Fax: 3465249759

Keywords: Bronchiolitis obliterans organizing pneumonia

occupational lung disease

organizing pneumonia

pulmonary toxicity

textile aerography

Received: February 111997

Accepted after revision July 101997

This work was supported in part by a grant: Fondo de Investigaciones Sanitarias de la Seguridad Social, No. 93/0935.
Organizing pneumonia (OP) is a clinicopathological entity characterized by histological evidence of intraluminal polyps of connective tissue in the distal pulmonary air spaces, contrasting with minor interstitial fibrosis, together with distinctive clinical and radiographic features. Although OP is frequently idiopathic, more and more cases with an identified cause or associated disease have been described, and the list is increasing [1]. The outcome is frequently favourable with excellent response to corticosteroids, despite its tendency to relapse. However, death may result from progressive disease in up to $8 \%$ of patients [2]. Cases associated with connective-tissue disease, autoimmune disease or exposure to drugs or environmental agents seem to be associated with a poor prognosis [3].

Recently, an outbreak of OP occurred among textile printing sprayers in factories in the Autonomous Community of Valencia, Spain. An epidemiological investigation proposed that the lung disease was caused by spraying procedures that delivered a respirable aerosol of Acramin-FWN to distal airways and pulmonary parenchyma [4]. AcraminFWN is a poliamidamine marketed by Bayer (Leverkusen, Germany), to be applied with a brush or sponge for textile printing.

The aim of this study was to describe in detail the clinical features of those textile printing sprayers in whom OP was demonstrated histologically.

$\overline{\text { For editorial comments see page } 259 .}$

\section{Methods}

\section{Patient population}

As part of an ongoing research effort to study workers exposed to textile aerography, which started in May 1992, a total of 257 workers from eight factories were identified. Among them, 111 workers (36 exposed to AcraminFWN) with suspected respiratory disease were referred to our hos-pital for further evaluation. Previously, in January 1992, we had cared for a woman who is now considered the in-dex case of the outbreak.

All patients were studied as in-patients and underwent an initial evaluation consisting of a history and physical examination, laboratory studies, chest radiographs, pulmonary function tests, fibreoptic bronchoscopy and tracheobronchial lung biopsy (TBB). In all, except the index case, this evaluation also included a chest computed tomography (CT) scan and bronchoalveolar lavage (BAL).

In 14 out of 98 patients in whom representative lung tissue was obtained, pathological changes consistent with OP were found. Eleven of these 14 patients were included as cases in the previous epidemiological study [4]. Due to the importance of this outbreak, this epidemiological study [4] was elaborated upon with the results of the first 88 transbronchial biopsies in the present study. 


\section{Occupational data}

All materials used in the eight factories over time were investigated. Thirty different products related to sprayprinting were identified.

All 14 patients had worked in two factories, previously referred to as A and B [4]. These two factories shared the use of five products, Acramin F system, throughout the study; Acramin-FWR had been replaced by AcraminFWN since June 1991. Time of employment at aerographic factories was used as a surrogate measure of exposure and is quantified in months, consisting of 4 weeks each of which consisted of 40 working hours. The time since Acramin-FWN was introduced was considered separately.

Spray printing of textiles was stopped by law at factory A in May 1992, and at factory B in July 1992.

\section{Clinical evaluation}

Symptoms were considered to be present if they appeared during or after dye exposure and were not attributable to another cause.

Epistaxis was defined by recurrent and significant nose bleeding. Cough was considered productive when sputum, other than scanty mucus, occurred. Dyspnoea was classified using a modified Medical Research Council (MRC) dyspnoea scale [5].

\section{Radiological evaluation}

The chest CT scans were obtained by using contiguous $10 \mathrm{~mm}$ collimation and selected $2.0 \mathrm{~mm}$ slices (high resolution computed tomography (HRCT)). Any presumed ab-normal infiltrate seen either on chest radiography or on CT scan was considered.

\section{Pulmonary function evaluation}

All functional determinations were performed using a Master-Lab assembly (Jaeger, Würzburg, Germany). Forced flow-volume loops were performed using a pneumotachograph in the standing position, a minimum of three suitable recordings were obtained and the best one was used. Static lung volumes were measured in a constant pressure body plethysmograph. The transfer factor of the lung was determined by the single-breath carbon monoxide method (TL,CO,sb). The reference values were those of the European Coal and Steel Community [6]. Functional impairment was considered to be present when measured values were lower than those corresponding to the fifth percentile of the distribution in a group of 109 healthy subjects, who had a homogeneous distribution with respect to the study group: forced vital capacity (FVC) $<89.9 \%$; forced expiratory volume in one second $(\mathrm{FEV} 1)<92.1 \%$; FEV1/FVC $<90.3 \%$; total lung capacity (TLC) $<84.5 \%$; residual volume $(\mathrm{RV})<65 \%$; TL,CO,sb $<74 \%$ and $T \mathrm{~L}, \mathrm{CO}, \mathrm{sb} /$ alveolar volume $(V \mathrm{~A})<68.6 \%$, expressed as percentage of reference values.

Methacholine provocation tests were performed using a tidal breathing method adapted from CocKCROFT et al. [7] and PRIETO et al. [8].
Values of arterial oxygen tension $\left(\mathrm{Pa}, \mathrm{O}_{2}\right)$, arterial carbon dioxide tension $\left(\mathrm{Pa}_{\mathrm{a}} \mathrm{CO}_{2}\right)$ and $\mathrm{pH}$ were measured using appropriate electrodes (IL 1306; Instrumentation Laboratory, Milano, Italy). Alveolar oxygen tension $\left(P \mathrm{~A}, \mathrm{O}_{2}\right)$ was calculated assuming a respiratory quotient of 0.8 .

\section{Fibreoptic bronchoscopy}

Fibreoptic bronchoscopy was performed in standard fashion using an Olympus B-20 bronchoscope (Olympus Optical Co., Hamburg, Germany). BAL was performed in an involved segment, using a total volume of $150 \mathrm{~mL}$ of $0.9 \%$ sterile saline in three $50 \mathrm{~mL}$ aliquots. TBB specimens from the area that appeared to be most abnormal on the chest radiograph were obtained using conventional fenestrated biopsy clamps.

\section{Pathological evaluation}

The lung tissue was fixed in $10 \%$ buffered formalin. Serial slides were stained with haematoxylin-eosin, periodic acid-Schiff (PAS), orcein-van-Gieson, and Masson's trichrome.

\section{Treatment}

Treatment was initiated in all patients just after the first evaluation at our hospital, even before a pathological confirmation of OP had been obtained. Treatment consisted in stopping occupational exposure and giving $1 \mathrm{mg} \cdot \mathrm{kg}^{-1} \cdot \mathrm{day}^{-1}$ oral prednisone for 3 months, tapered to $0.5 \mathrm{mg} \cdot \mathrm{kg}^{-1} \cdot \mathrm{day}^{-1}$ for the following 3 months and then the prednisone was gradually tapered to zero for a total of 12 months. If clinical or functional deterioration occurred, intravenous methylprednisolone, $\mathrm{N}$-acetylcysteine or oral cyclophosphamide were considered

\section{Follow-up}

After discharge, patients were re-evaluated monthly during the first year, and then every 3-6 months. Each follow-up evaluation included symptoms, a physical examination, chest radiographs, and pulmonary function tests. Patients were kept in close contact with the Respiratory Unit by means of telephone and direct access.

\section{Statistical analysis}

Data were stored in D-base III+(V1.0, Ashton Tale 1987, California, USA) and statistical analysis was performed using the Statistical Package for the Social Sciences (SPSS)/PC+ V4.01 software (SPSS, Chicago, IL, USA). McNemar's test was used to compare the prevalence of an abnormality between two different evolutive times: at admission and at the moment of worst pulmonary function test (lowest FVC) in each patient.

For studying predictors of mortality, the Mann Whitney U-test was used for continuous variables, and Fisher's exact test for categorical variables [9]. Multiple logistic regression models were used to adjust the odds ratios for potentially confounding variables. A p-value of less than 0.05 was considered significant. 


\section{Results}

The mean $( \pm S D)$ age of the 14 patients studied (nine females), was $30 \pm 14$ yrs (range 18-57). Six workers were smokers, with a mean of $2.8 \pm 2.1$ pack years (range $0.5-$ $5)$. Before working in textile aerography, one employee presented symptoms compatible with chronic bronchitis and another had a history of rhinitis since childhood.

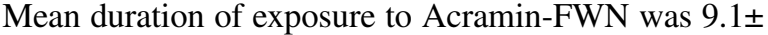
3.5 months (range 2.8-13.7), and the mean interval between leaving work and admission was $3.1 \pm 5.3$ months (median 0.8; range 0-20.2). The mean duration of exposure to textile dye products was $20.6 \pm 14.6$ months (range $2.8-$ 48).

\section{Illustrative case reports}

Index case. On January 3, 1992 we studied a female aged 28 yrs with a 3 month history of productive cough, nose bleeding, progressive shortness of breath and oppressive chest pain. An interstitial infiltrate on chest radiograph and severe restrictive impairment of lung function (FVC $30 \%$ of predicted) were evident. In the last year, she had worked in factory A. TBB showed evidence of OP. Despite treatment with corticosteroids and supportive care measures, the patient showed relentless progressive pulmonary disease that ended in fatal respiratory failure on February 15, 1992

Case 1. A male aged 53 yrs was referred to our Hospital on July 28, 1992 for abnormalities in chest radiography. He had worked for 4 yrs, until 2 months before admission, in factory B. Except for intermittent epistaxis during the last 2 years, he was asymptomatic and physical examination and laboratory results showed no abnormalities.

Radiographic studies demonstrated patchy bilateral alveolar infiltrates (fig. 1). FVC was $3.42 \mathrm{~L} \mathrm{(83 \%} \mathrm{of} \mathrm{pred-}$ icted), FEV1/FVC 104\% pred, TLC 5.36 L (82\% pred) and $T \mathrm{~L}, \mathrm{CO}, \mathrm{sb} 8.7 \mathrm{mmol} \cdot \mathrm{min}^{-1} \cdot \mathrm{kPa}^{-1}(92 \%$ pred). The alveolar-arterial oxygen difference $\left(P \mathrm{~A}-\mathrm{a}, \mathrm{O}_{2}\right)$ was $2.5 \mathrm{kPa}(19$ $\mathrm{mmHg}$ ). Bronchoscopy and BAL revealed no abnormalities, while TBB showed OP. Treatment with prednisone resulted in functional improvement $(\mathrm{FVC} 3.90 \mathrm{~L})$ within 1 month. However, 15 days later, the patient developed progressive dyspnoea, fever, diffuse crackles, elevation of erythrocyte sedimentation rate (ESR) $\left(95 \mathrm{~mm} \cdot \mathrm{h}^{-1}\right)$ and serum lactate dehydrogenase (LDH) (731 U. $\left.\mathrm{L}^{-1}\right)$, progression of radiographic infiltrates (fig. 2), decline of pulmonary function tests, and progressive hypoxaemia requiring mechanical ventilation on October 9, 1992. Three days later, an open lung biopsy did not detect any infectious cause of the rapid respiratory failure. He died on October 14, 1992.

Case 2. A female aged 21 yrs was submitted for study on May 11, 1992. She had a history of episodic hydrorrhea, sneeze and conjunctival injection since childhood. She had worked in factory A from January to April 1992. A few weeks after exposure she developed recurrent epistaxis, cough with purulent sputum, and nocturnal wheezing. Physical and laboratory examinations were normal. Chest radiograph and $\mathrm{CT}$ scan showed diffuse small nodular infiltrates. FVC was $2.57 \mathrm{~L}$ (68\% pred), FEV1/VC $113 \%$ pred, TLC 4.05 L (82\% pred), RV/TLC $35 \%$ (134\% a)

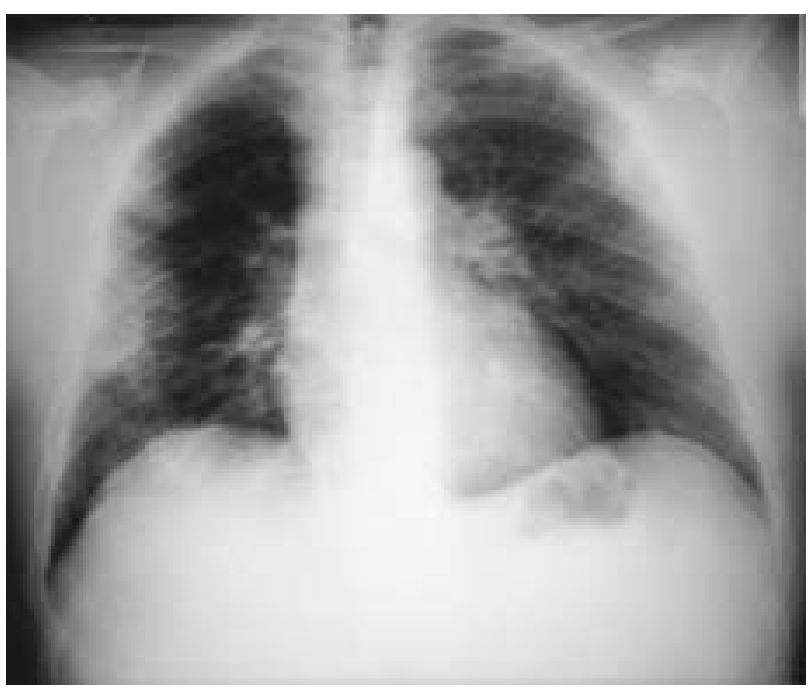

b)

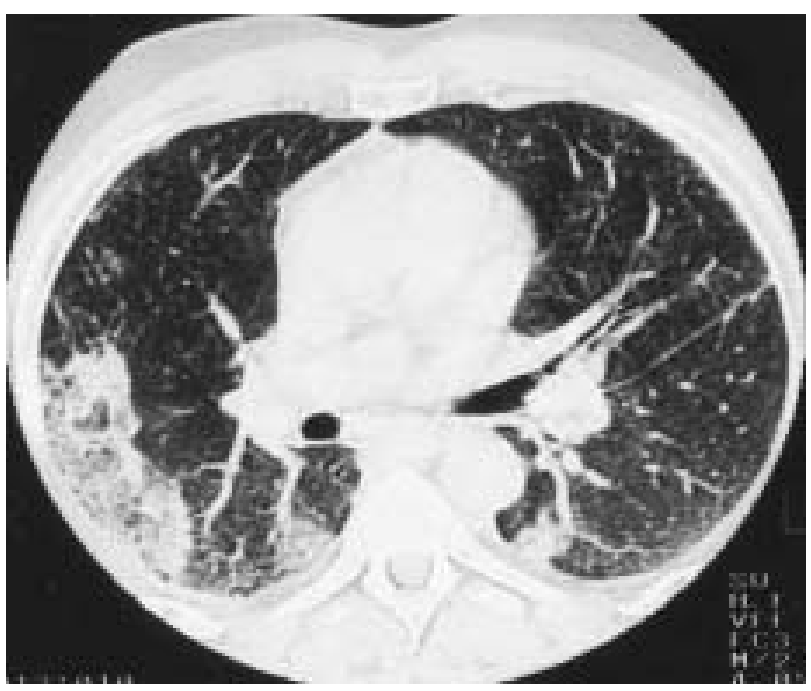

Fig. 1. - Patchy bilateral infiltrates on: a) the chest radiograph; with b) predominantly subpleural distribution on high resolution computed tomography (HRCT).

pred). $P \mathrm{~A}-\mathrm{a}, \mathrm{O}_{2}$ was $0.8 \mathrm{kPa}(6 \mathrm{mmHg})$. TBB showed OP. After 4 weeks of treatment with prednisone, cough decreased, sputum production and wheezing ceased with simultaneous reduction of RV/TLC (24\%). However, two months later the patient began a downward course with progressive dyspnoea on effort and progression of the infiltrates on radiographic studies. Oral cyclophosphamide, $\mathrm{N}$-acetylcysteine and vitamin $\mathrm{C}$ were added. Despite therapeutic changes FVC decreased at a rate of about $150 \mathrm{~mL}$. week ${ }^{-1}$. In January, 1993 the patient underwent double pulmonary transplantation a few hours after requiring mechanical ventilation for respiratory failure. The patient was still alive and well 33 months after transplantation.

\section{Clinical presentation}

Epistaxis (in nine patients (64\%)) and cough (in four patients $(29 \%)$ ) were the first symptoms reported by patients. 
a)

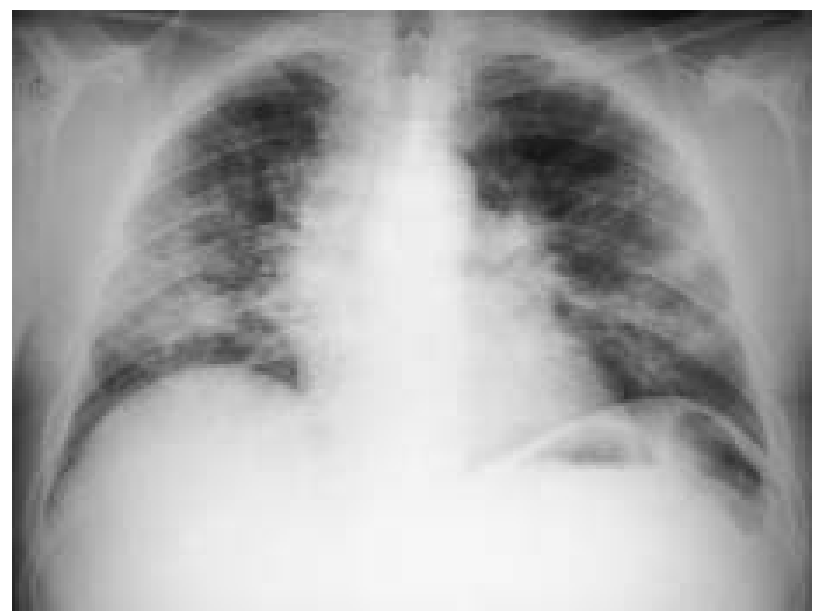

b)

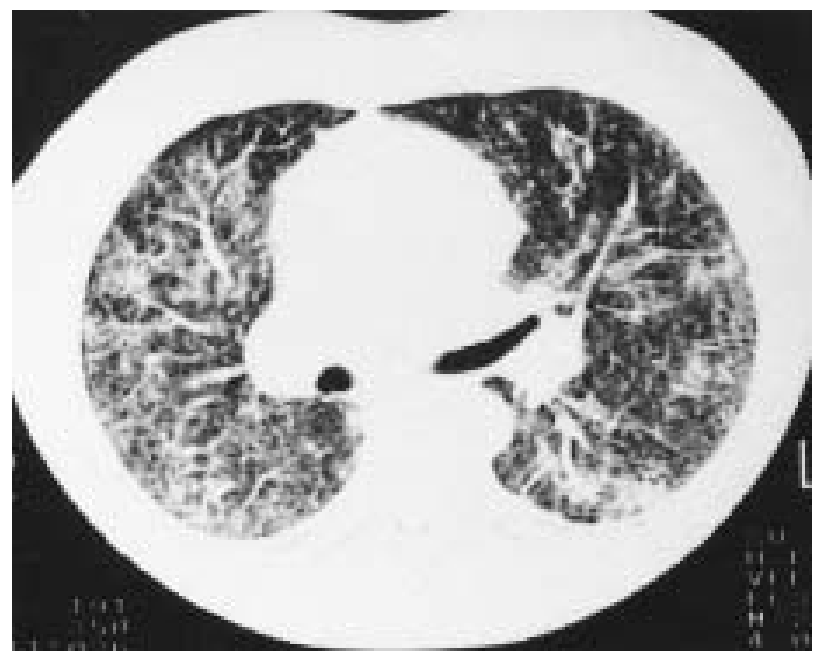

Fig. 2. - Progression of diffuse alveolar and interstitial infiltrates on: a) the chest radiograph; and b) high resolution computed tomography (HRCT) of the same patient as in figure 1

Among the 11 patients who worked in aerography before the use of Acramin-FWN, nine showed symptoms before its introduction and in two the first symptom, cough, appeared 5 and 7 months later, respectively. Two patients, who started working after the introduction of AcraminFWN, developed epistaxis within 15 days of exposure.

Cough and epistaxis were also the most common symptoms on admission (table 1). Cough was usually persistent, and was productive in almost half the cases. Chest pain, initially present in five patients, was usually characterized by a feeling of substernal tightness. Four patients complained of dyspnoea of different intensity, classes IIV. A history of flu-like illness or malaise was not elicited in any of the patients.

Tachypnoea ( $>20$ breaths $\left.\cdot \mathrm{min}^{-1}\right)$ was found in five patients, and dry crackles in three of them. Fever and wheezing were absent.

Haematological parameters and liver and renal function tests were within normal limits in all patients. Only the index patient, already in an advanced disease stage, had an ESR of $22 \mathrm{~mm} \cdot \mathrm{h}^{-1}$. Serum levels of antinuclear antibodies, rheumatoid factor and complement were normal.
Table 1. - Prevalence of clinical findings and abnormal laboratory results in 14 patients with organizing pneumonia at the time of admission and at the time of maximal decrease in forced vital capacity (FVC)

\begin{tabular}{|c|c|c|c|c|c|}
\hline & \multicolumn{2}{|c|}{ At admission } & \multicolumn{2}{|c|}{$\begin{array}{c}\text { At time of } \\
\text { maximal } \\
\text { decline in FVC }\end{array}$} & \multirow[b]{2}{*}{ p-value } \\
\hline & $\mathrm{n}$ & $(\%)$ & $\mathrm{n}$ & $(\%)$ & \\
\hline Cough & 11 & (78.6) & 12 & $(85.7)$ & 0.62 \\
\hline Sputum & 5 & (35.7) & 6 & (42.8) & 0.69 \\
\hline Epistaxis & 10 & (71.4) & 2 & (14.3) & 0.016 \\
\hline Chest pain & 5 & (35.7) & 8 & (57.1) & 0.19 \\
\hline Shortness of breath & 4 & 28.6) & 9 & (64.3) & 0.06 \\
\hline $\begin{array}{l}\text { Respiratory frequency } \\
>20 \text { breaths } \cdot \mathrm{min}^{-1}\end{array}$ & 5 & $(35.7)$ & 6 & $(42.8)$ & 0.69 \\
\hline Crackles & 3 & (21.4) & 7 & $(50.0)$ & 0.06 \\
\hline $\begin{array}{l}\text { Leucocytosis }>12,000 \\
\text { cells } \cdot \mathrm{mm}^{-3}\end{array}$ & 1 & $(7.1)$ & 4 & $(28.6)$ & 0.125 \\
\hline ESR >20 mm.h-1 & 1 & (7.1) & 4 & $(28.6)$ & 0.125 \\
\hline $\mathrm{LDH}>460 \mathrm{IU} \cdot \mathrm{L}^{-1}$ & 0 & $(0)$ & 5 & (38.2) & 0.06 \\
\hline
\end{tabular}

ESR: erythrocyte sedimentation rate; LDH: serum lactate dehydrogenase.

No changes were observed in urinary sediment. Serologic tests, including titres for influenza, adenovirus, Mycoplasma pneumoniae, and Legionella showed no evidence of recent infection.

Chest radiographs were abnormal in $86 \%$ (12 out of 14) of patients and showed a mixed pattern: predominantly patchy alveolar infiltrates in seven patients and an interstitial pattern in five. The infiltrates were bilateral and diffuse in all patients, although those of alveolar type predominated in lower lobes. CT of the chest showed bilateral, predominantly patchy air-space consolidation with a subpleural distribution in nine patients and diffuse small nodular infiltrates in four.

The mean FVC ( $90.3 \%$ pred), FEV1 (90\% pred), TLC (93.3\% pred) and TL,CO,sb (91.5\% pred) were significantly lower $(\mathrm{p}<0.05)$ within the patient group than within the control group. Multiple regression analysis examining the combined influence of RV(\% pred) and TLC (\% pred) on $\mathrm{VC}(\%$ pred) showed that aerographic exposure led to reductions in VC, primarily by reducing TLC $(\mathrm{VC}=-1.7+$ 1.4×TLC-0.4 RV).

Six patients showed a restrictive ventilatory defect (TLC $<84.5 \%$ pred), another patient showed an isolated reduction in TL,CO,sb, and an obstructive defect (FEV1/ FVC $<90.3 \%$ ) was evident in two patients. Pulmonary function tests were normal in five $(36 \%)$ patients. The methacholine challenge testing was positive in four out of nine patients (44\%), including the two patients with obstructive defect. Resting arterial blood gas determinations while breathing room air revealed minor increases of $P A-a, O_{2} 2.3$ to $2.5 \mathrm{kPa}$ ( 17 to $19 \mathrm{mmHg}$ ) in three patients.

The mean volume of BAL fluid recovered was $65.3 \pm$ $18.3 \mathrm{~mL}$ (range $33-98 \mathrm{~mL}$ ). The total cell count was $15.0 \pm 16.1 \times 10^{6}$ cells $100 \mathrm{~mL}^{-1}$ (range $1.6-61.5 \times 10^{6}$ cells. $\left.100 \mathrm{~mL}^{-1}\right)$. The differential was: macrophages $80.5 \pm 9.5 \%$ (range 65-97\%), neutrophils 3.6 $\pm 2.4 \%$ (range 1-9\%) and T-lymphocytes $14.7 \pm 8.7 \%$ (range $2-30 \%$ ). Six patients showed $>15 \%$ of T-lymphocytes in the differential analysis, and in two of them the CD4/CD8 ratio was $<1$. Bacteriological studies of the BAL were negative. 
Table 2. - Prevalence of abnormal pulmonary function tests in 14 patients with organizing pneumonia at admission and at the time of maximal decrease in forced vital capacity (FVC)

\begin{tabular}{lrrrrr}
\hline & \multicolumn{2}{c}{$\begin{array}{c}\text { At } \\
\text { admission }\end{array}$} & \multicolumn{2}{c}{$\begin{array}{c}\text { At time of } \\
\text { maximal } \\
\text { decline in FVC }\end{array}$} & p-value \\
\hline FVC $<89 \%$ pred & $5 / 14$ & $(35.7)$ & $10 / 14$ & $(71.4)$ & 0.06 \\
FEV $1 /$ FVC $<92.1 \%$ & $2 / 14$ & $(14.3)$ & $0 / 14$ & $(0)$ & NS \\
TLC $<84.5 \%$ pred & $6 / 13$ & $(46.1)$ & $8 / 13$ & $(61.5)$ & NS \\
RV $<65 \%$ pred & $1 / 13$ & $(7.7)$ & $6 / 13$ & $(46.1)$ & 0.06 \\
$T L, C O$, sb $<74 \%$ pred & $1 / 11$ & $(9.1)$ & $7 / 11$ & $(63.6)$ & 0.03 \\
TL,CO,sb/VA & $3 / 11$ & $(27.3)$ & $1 / 11$ & $(9.1)$ & N \\
$\quad<68.6 \%$ pred & & & & &
\end{tabular}

Values are presented as number of subjects/total number, and percentages in parenthesis. FEV1: forced expiratory volume in one second; TLC: total lung capacity; RV: residual volume; $T \mathrm{~L}, \mathrm{CO}, \mathrm{sb}$ : single breath transfer factor of the lung for carbon monoxide; VA: alveolar volume.

\section{Clinical course}

The mean follow-up was 17 months (range 1.5-38 months). Within the first months of treatment, $10(71 \%)$ patients experienced a drop in FVC that amounted to a mean of $896 \pm 403 \mathrm{~mL}$ (range $280-1,430 \mathrm{~mL}$ ), and was preceded in four patients by a short-lived improvement. The time elapsed between admission and the moment of maximum decline in FVC for each subject ranged 12-35 weeks (mean $17 \pm 12$ weeks). In this period, there was also a net increase in the prevalence of abnormal values for RV and TL,CO,sb (table 2).

Apart from epistaxis, which resolved following removal from exposure in eight of the 10 patients, usually before 1 month, a decline in FVC was accompanied by persistence or worsening of previous symptoms or the appearance of new ones (table 1). Patients with a fatal outcome suffered, especially in the most advanced stages of their disease, from fever and a consistent increase in white cell count, serum LDH and ESR.

In five patients, the disease progressed to respiratory failure, 1.5-8 months after the initial evaluation. Four patients died showing typical features of adult respiratory distress syndrome, and one survived after bilateral lung transplantation.

Apart from those who died, four patients required an adjustment to their corticosteroid dosage on nine occasions, sometimes in the form of an intravenous bolus for short periods of time, due to deterioration; in one patient corticosteroids were re-introduced because of a relapse. Three patients received additional therapy with cyclophosphamide. All surviving patients showed pulmonary function tests values within the normal range 3-31 months after stopping treatment. Minor radiographic interstitial changes, better appreciated on HRCT, were evident in most patients.

\section{Pathological studies}

On the first evaluation, 10 patients were diagnosed as having OP: nine by TBB and one by open lung biopsy. In two additional patients, the diagnosis was obtained by repeated TBB after 5 months of treatment. In the two remaining patients pathological proof of OP was only obtained postmortem.

Changes due to OP consisted of intraluminal tufts of loose connective tissue occupying alveolar ducts and alveoli. The surrounding alveoli commonly demonstrated a mild chronic interstitial infiltrate, foamy macrophages and reactive type II pneumocytes (fig. 3). Biopsies of the index case, and four biopsies obtained in three patients, 6 months after the first evaluation, showed mild mural fibrosis and changes suggestive of mural incorporation of airspace fibrosis (fig. 4). An open biopsy performed in a

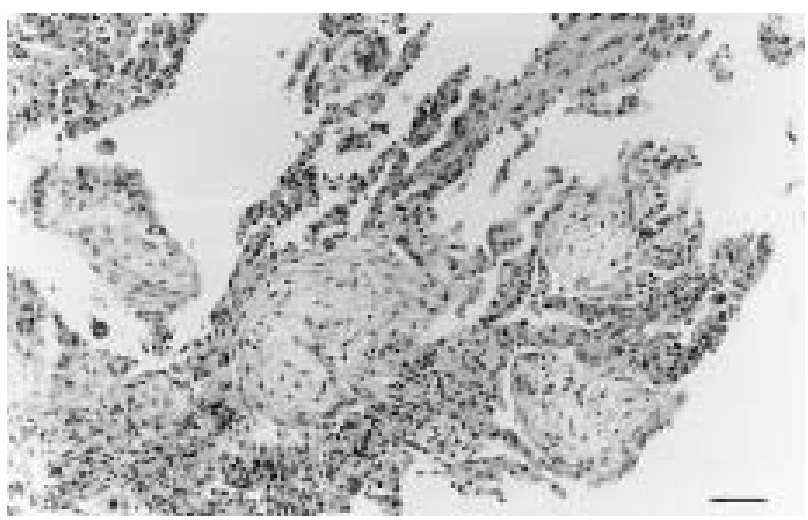

Fig. 3. - Polypoid plugs of immature-appearing fibroblastic tissue within peripheral air spaces. Haemotoxylin and eosin stain. Internal scale bar $=100 \mu \mathrm{m}$.

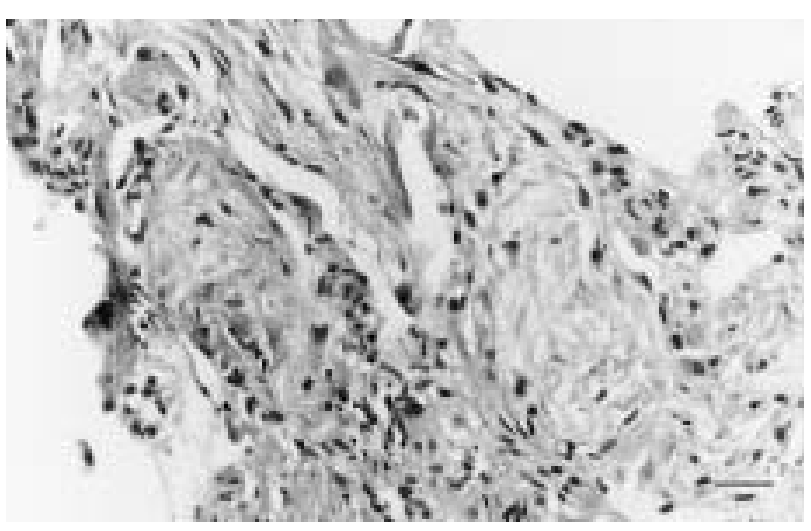

Fig. 4. - Loose connective tissue incorporated into an alveolar wall. Haemotoxylin and eosin stain. Internal scale bar $=50 \mu \mathrm{m}$.

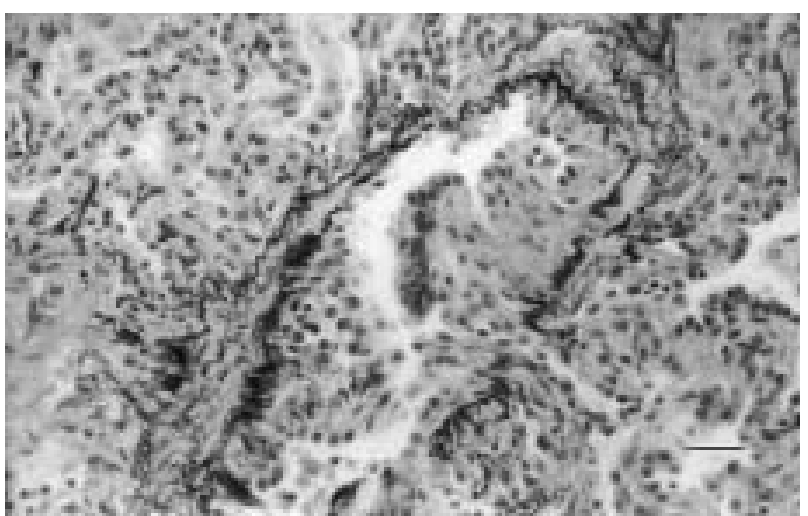

Fig. 5. - Fibrous tissue proliferation partially occluding the lumen of a bronchiole. Orcein-van Gieson stain. Internal scale bar $=50 \mu \mathrm{m}$. 


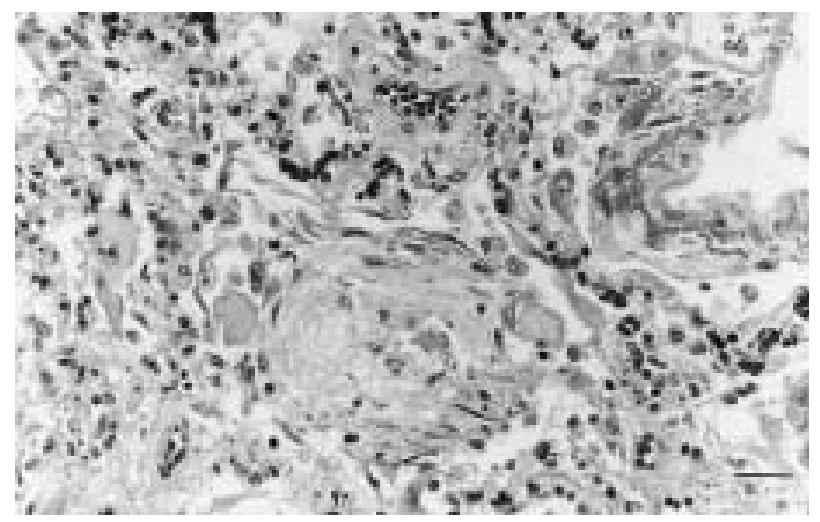

Fig. 6. - Autopsy lung specimen showing organizing pneumonia associated with diffuse alveolar damage, prominent hyperplasia of type II pneumocytes and hyaline membranes. Masson's trichrome stain. Internal scale bar $=50 \mu \mathrm{m}$.

worker 20 months after the exposure revealed intra-alveolar and intrabronchiolar buds of granulation tissue, some being organized into collagen fibrosis (fig. 5), together with areas of interstitial fibrosis. Specimens from the three necropsies and the explanted lungs, in addition to OP showed, invariably, changes of diffuse alveolar damage with hyaline membranes (fig. 6) and fibroblastic interstitial proliferation as well as severe mural fibrosis. The alveolar architecture was largely lost, and broad tracts of fibrosis alternated with disorganized air spaces, often lined by bronchioloal-veolar hyperplastic epithelium with focal squamous metaplasia. The examination of other thoracoabdominal organs did not show any meaningful alteration.

Tissue specimens tested negative for bacteria, mycobacteria and fungi and no evidence was obtained of granulomata or vasculitis in any patient.

\section{Predictors of mortality}

No significant correlation was found between mortality and either expositional variables or initial symptoms, or with laboratory results on admission or BAL. However, all five patients who died, but only one of nine who survived $(p<0.01)$, had decreased values of TLC on admission. FVC, presence of crackles and respiratory rate on admission also showed significant influence on mortality $(\mathrm{p}<0.05)$ as did the progressive increase of $P \mathrm{~A}-\mathrm{a}, \mathrm{O}_{2}(\mathrm{p}<0.02)$. Multivariate logistic models using values on admission, as well as maximally increased laboratory measurements during follow-up, showed no clear association with mortality.

\section{Discussion}

During the outbreak of respiratory disease that occurred in aerography industries in the Valencia Community in 1992, OP was histologically proven in 15 patients: the 14 patients described in the present study and an additional patient who died of respiratory failure in April 1992 at another hospital. All these patients had been exposed to Acramin-FWN, the toxicant likely to be the cause of the most severe forms of the disease.

The illness, being caused by an inhaled agent, was restricted to the respiratory system. Epistaxis, symptoms of bronchitis, dyspnoea, and chest pain derived from the acinar fibrotic process were nearly always the only symptoms. The presence of epistaxis and cough in some patients before Acramin-FWN was introduced, suggest that these symptoms were not exclusively related to this compound, but may also have resulted from exposure to one or more other chemicals used in the aerography industries.

Fever, leucocytosis, and increased ESR appeared only in the final disease stages. As neither culture, nor biopsy specimens, nor serum titers against various infective agents revealed any infectious event which could be responsible for the deterioration, these findings are considered compatible with an acute fibrotic inflammatory process such as that seen in acute interstitial pneumonia and late adult respiratory distress syndrome [10-13]. The changes in liver chemistry seen in some forms of cryptogenic organizing pneumonia (COP), which suggest intrahepatic cholestasis [14], were consistently absent in our patients. The increase in serum LDH observed during the respiratory failure stage, may be related to final acute lung damage and not to hepatic impairment.

As in patients with idiopathic forms of OP, those with OP following exposure to Acramin-FWN showed areas of airspace consolidation or multiple small nodular opacities as the predominant radiographic finding. Nonetheless, the proportion of those with a predominant nodular pattern $(36 \%)$ was higher than in other studies $[2,15]$ and in patients with a progressive course, an added coarse reticular pattern, more consistent with chronic interstitial pneumonia, was observed later.

COPD, as well as bronchiolitis obliterans organizing pneumonia (BOOP), have been described as syndromes associated with the development of a restrictive lung defect, although combined and obstructive profiles have also been reported [2]. In the present study, most patients exhibited a progressive decline in lung volumes and $T \mathrm{~L}, \mathrm{CO}, \mathrm{sb}$, while FEV1 fell to a lesser extent than FVC, resulting in an increased FEV1/FVC ratio. Even a mild obstructive defect, as initially observed in two patients, was later overshadowed by restriction during the active stage of the disease. These results reflect an overall progression of diffuse interstitial pulmonary involvement, as repeated histological studies have demonstrated in some of our patients.

The initial BAL findings were unremarkable. A mild increase in lymphocyte count was found in some patients, but without demonstrable relation to the histological findings, response to corticosteroid therapy, or outcome.

Although the pathological appearance of OP is nonspecific, it often indicates the presence of an ongoing, and potentially treatable, process and in fact most cryptogenic cases show an excellent response to corticosteroids. In a review of the literature including 252 patients with COP, most (218 out of 252) of them were reported as being idiopathic. Alasaly et al. [2] found that $163(64.6 \%)$ recovered completely, $69(27.3 \%)$ improved, but had residual abnormalities, and $20(7.9 \%)$ died. However, the outcome varies between different series, and seems to be related to aetiology. Together with cases associated with connective tissue disease or autoimmune disease, a poor prognosis has been attributed to those forms resulting from exposure to environmental agents [3]. In the present outbreak, despite treatment and avoidance of further exposure, 11 out of 14 patients followed a progressive decline in pulmonary function that resulted in terminal respiratory insuffi- 
ciency in five of them (36\%). These figures confer a distinctly poor prognosis to the disease resulting from Acramin-FWN exposure. However, as transbronchial lung biopsy was the initial diagnostic technique used, and because this procedure may underestimate the actual number of patients affected pathologically [16], and repeated diagnostic approaches were limited to those patients with a progressive evolution, an overestimate of the percentage of patients with unfavourable outcome cannot be ruled out.

Since Lowry and Schuman [17] in 1956 reported rapid improvement with the use of corticosteroids in two patients with bronchiolitis obliterans after exposure to silo gas, these therapeutic agents have been used both to treat and to prevent fume-related bronchiolitis. If treatment is to be effective, the need for early intervention in the course of the disease has been stressed [18]. In the present outbreak, the fact that patients with more preserved lung function tests when steroids were initiated showed a significantly better outcome, is consistent with the benefit of early treatment. Nevertheless, given the initial insidious course of the disease, by the time the diagnosis was made a long period had elapsed and the resultant lung injury was probably severe enough to be progressive and in some cases could not be controlled, despite treatment.

However, in nonlethal cases, recovery was the rule, and despite minimal residual radiographic changes, pulmonary function returned to normal.

The paucity and mild intensity of symptoms in patients while being exposed, together with a long and variable latency period may (outside an outbreak, such as that reported here) make the distinction between this new inhalant-related form of organizing pneumonia and idiopathic forms difficult. As novel environmental causes for organizing pneumonia are being increasingly recognized [19, 20], every effort should be made to determine occupational exposure in patients with apparently cryptogenic forms of organizing pneumonia in order to more fully understand and prevent this potentially devastating illness.

\section{References}

1. Epler GR. The clinician's classification of the diseases of the bronchioles. In: Epler GR, ed. Diseases of the Bronchioles. Raven Press, New York, 1994; 101-112.

2. Alasaly K, Muller N, Ostrow DN, Champion P, Fitzgerald JM. Cryptogenic Organizing Pneumonia. A report of 25 cases and a review of the literature. Medicine 1995; 74: 201-211.

3. Costabel U, Guzman J, Teschler H. Bronchiolitis obliterans with organizing pneumonia: outcome. Thorax 1995; 50 (Suppl 1): 59s-64s.
4. Moya C, Antó JM, Newman Taylor AJ, and Collaborative Group for the Study of Toxicity in Textile Aerographic Factories. Outbreak of organizing pneumonia in textile printing sprayers. Lancet 1994; 343: 498-502.

5. Official statement of the American Thoracic Society. Surveillance for respiratory hazards in the occupational setting. Am Rev Respir Dis 1982; 126: 952-956.

6. Quanjer PH, ed. Standardized lung function testing. Report of working party for "Standardization of lung function tests". European Community for Coal and Steel. Luxembourg. Bull Eur Physiopathol Respir 1983; 19 (Suppl. 5): 1-95.

7. Cockcroft DW, Killian DN, Mellon JJA, Hargreave FE. Bronchial reactivity to inhaled histamine: a method and clinical survey. Clin Allergy 1977; 7: 235-243.

8. Prieto L, Bertó JM, Gutierrez V, Tornero C. Effect of inhaled budesonide on seasonal changes in sensitivity and maximal response to methacholine in pollen-sensitive asthmatic subjects. Eur Respir J 1994; 7: 1845-1851.

9. Norman GR, Streiner DL. Biostatistics: the bare essentials. Mosby Year Book, Inc, St. Louis, 1994; 153-156.

10. Kazenstein ALA, Myers JL, Mazur MT. Acute interstitial pneumonia: a clinicopathologic, ultrastructural, and cell kinetic study. Am J Surg Pathol 1986; 10: 256-267.

11. Olson J, Colby TV, Elliot CG. Hamman-Rich Syndrome revisited. Mayo Clin Proc 1990; 65: 1538-1548.

12. Meduri GU, Beleuchia JM, Estes RJ, Wundering RG, Torki ME, Leeper KV. Fibroproliferative phase of ARDS: clinical findings and effects of corticosteroids. Chest 1991; 100: 943-952.

13. Kondoh Y. Acute exacerbation in idiopathic pulmonary fibrosis: Analysis of clinical and pathologic findings in three cases. Chest 1993; 103: 1808-1812.

14. Spiteri M, Klenerman P, Sheppard MN, Padley S, Clark TJK, Newman-Taylor A. Seasonal cryptogenic organising pneumonia with biochemical cholestasis: a new clinical entity. Lancet 1992; 340: 281-284.

15. Epler GR, Colby TV, McLoud TC, Carrington CB, Gaensler EA. Bronchiolitis obliterans organizing pneumonia. N Engl J Med 1985; 312: 152-158.

16. Geddes DM. BOOP and COP. Thorax 1991; 46: 545547.

17. Lowry T, Schuman LM. "Silo-filler's disease": a syndrome caused by nitrogen dioxide. JAMA 1956; 162: 153-160.

18. Moran TJ, Hellstrom HR. Bronchiolitis obliterans: an experimental study of the pathogenesis and the use of cortisone in modification of the lesions. AMA Arch Pathol 1958; 66: 691-707.

19. White ChS, Templeton A. Chemical penumonitis. Radiol Clin North Am 1992; 30: 1231-1243.

20. Haim DY, Lippman ML, Goldberg SK, Walkenstein MD. The pulmonary complications of crack cocaine. A comprehensive review. Chest 1995; 107: 233-240. 